\title{
Analysis of residual stress in subsurface layers after precision hard machining of forging tools
}

\author{
Andrej Czan ${ }^{1, *}$, Jozef Holubjak ${ }^{1}$, Igor Daniš ${ }^{1}$, Juraj Martinček ${ }^{1}$, Matej Mikloš ${ }^{1}$, \\ Robert Čep $^{2}$, Michal Hatala ${ }^{3}$, Šarka Malotova ${ }^{2}$ \\ ${ }^{1}$ Faculty of Mechanical Engineering, University of Zilina, Univerzitna 8215/1, 01026 Zilina, \\ Slovakia \\ ${ }^{2}$ Faculty of Mechanical Engineering, VŠB - Technical University of Ostrava, 17. Listopadu 15/2172 \\ 708 33, Ostrava, Czech Republic \\ ${ }^{3}$ Faculty of Manufacturing Technologies Technical University of Košice with a seat in Presov, \\ Bayerova 1, 08001 Presov, Slovakia
}

\begin{abstract}
This paper is focused on analysis of residual stress of functional surfaces and subsurface layers created by precision technologies of hard machining for progressive constructional materials of forging tools. Methods of experiments are oriented on monitoring of residual stress in surface which is created by hard turning (roughing and finishing operations). Subsequently these surfaces were etched in thin layers by electro-chemical polishing. The residual stress was monitored in each etched layer. The measuring was executed by portable X-ray diffractometer for detection of residual stress and structural phases. The results significantly indicate rise and distribution of residual stress in surface and subsurface layers and their impact on functional properties of surface integrity.
\end{abstract}

Keywords: x-ray diffraction, residual stress, triaxial stress tensor, high feed machining

\section{Residual stress in subsurface layers}

Residual stresses are an integral part of produced workpieces, whether they are introduced deliberately, as a part of the design, as a by-product of a process carried out during the manufacturing process, or are present as the product of the component's service history. Residual stresses are additive with the stresses existing in the workpieces as a result of service loads. Clearly, they may be considered beneficial to the workpieces and therefore desirable, they may be irrelevant and can be ignored, or they are a potential detriment to the workpieces and their continued service life $[1,2,3]$. In practice, residual stress is stress which affects the entire volume of part or the majority of itself, i.e. macroscopic character. For full classification, it should be noted that residual stresses are called sometimes as technological stresses, because they arise from the action of technological processes during the producing of parts. Direction of residual stress (tension or compression) depends on the

\footnotetext{
${ }^{*}$ Corresponding author: andrej.czan@fstroj.uniza.sk

Reviewers: Ivan Kuric, Alžbeta Sapietová
} 
kind of deformation. Permanent residual stresses have the largest share on the functionality of part, and they cannot be detected by conventional methods $[4,5,6]$.

Stress conditions are ones of demonstrations of used machining technologies. After manufacturing process, they remain in parts and constructions and they operate continuously even without load. Their impact significantly affects the functionality of machined surfaces $[2,7]$.

Normal stress is defined as the stress acting normal to the surface of a plane; the plane on which these stresses are acting is usually denoted by subscripts. For example, consider the general case as shown in Figure 1, where stresses acting normal to the faces of an elemental cube are identified by the subscripts that also identify the direction in which the stress acts, e.g. $\sigma_{x}$ is the normal stress acting in the $x$ direction. Since $\sigma_{x}$ is a normal stress it must act on the plane perpendicular to the $\mathrm{x}$ direction. The convention used is that positive values of normal stress de-note tensile stress, and negative values denote a compressive stress $[8,9,10]$.

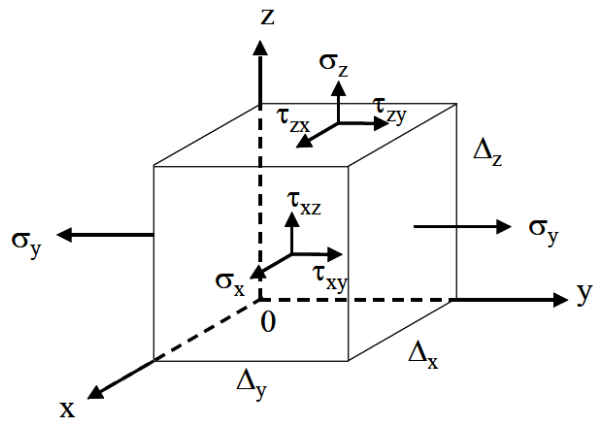

Fig. 1. Scheme of triaxial stress acting on an elemental unit cube [10]

Macroscopic stresses, which extend over distances that are large relative to the grain size of the material, are of general interest in design and failure analysis. Macroscopic stresses are tensor quantities, with magnitudes varying with direction at a single point in a component. The macroscopic stress for a given location and direction is determined by measuring the strain in that direction at a single point. When macroscopic stresses are determined in at least three known directions, and a condition of plane stress is assumed, the three stresses can be combined using Mohr's circle for stress to determine the maximum and minimum residual stresses, the maximum shear stress, and their orientation relative to a reference direction. Macroscopic stresses strain many crystals periodically in the surface. This periodical distortion of the crystal lattice shifts the angular position of the diffraction peak selected for residual stress measurement $[1,11,12]$.

Microscopic stresses are scalar properties of the sample, such as percent of cold work or hardness, which are without direction and result from imperfections in the crystal lattice. Microscopic stresses are associated with strains within the crystal lattice that traverse distances on the order or less than the dimensions of the crystals. Microscopic stresses change within the crystal lattice, altering the lattice spacing and broadening the diffraction peak. Macroscopic stresses and microscopic stresses can be determined individually from the diffraction peak position and breadth $[5,13,14]$. 


\section{Principles of X-ray diffraction stress measurement}

$\mathrm{X}$-ray diffraction is specific method that can measure residual stress quantitatively in crystalline and semi-crystalline materials, which include virtually all metals and their alloys, and most ceramic materials $[7,8,15]$.

The residual stress determined using X-ray diffraction is the arithmetic average stress in a volume of material defined by the irradiated area, which may vary from square centimeters to square millimeters, and the depth of penetration of the X-ray beam. The linear absorption coefficient of the material for the radiation used governs the depth of penetration, which can vary considerably. However, in iron, nickel, and aluminium-based alloys, $50 \%$ of the radiation is diffracted from a layer approximately $0.005 \mathrm{~mm}$ deep for the radiations generally used for stress measurement. This shallow depth of penetration allows determination of macro and microscopic residual stresses as functions of depth, with depth resolution approximately 10 to 100 times that possible using other methods. Although in principle virtually any interplanar spacing may be used to measure strain in the crystal lattice, the availability of the wavelengths produced by commercial X-ray tubes limits the choice to a few possible planes. The choice of a diffraction peak selected for residual stress measurement impacts significantly on the precision of the method. The higher the diffraction angle, the greater the precision. Practical techniques generally require diffraction angles, $2 \theta$, greater than $120^{\circ}[4,16]$.

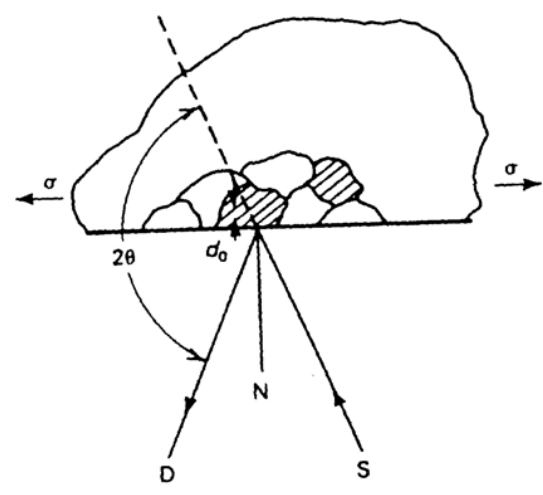

a)

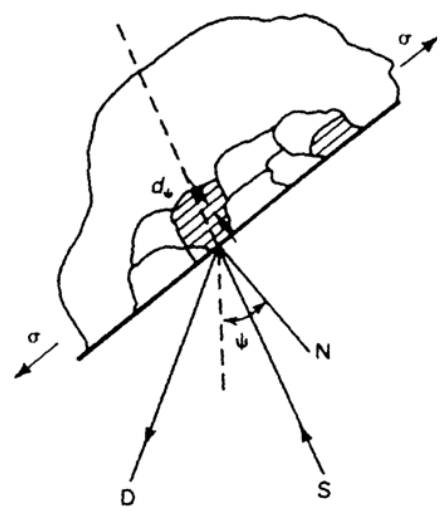

b)

Fig. 2. (a) out rotation $\psi=0$. (b) angle of rotation $\psi=\psi$ sample rotated through some known angle $\psi$, D- detector: S- source; N - normal to the surface.

Figure 2 describes the diffraction of a monochromatic beam of X-rays at a high diffraction angle $2 \theta$ from the surface of a stressed sample for two orientations of the sample relative to the X-ray beam. The angle $\psi$, defining the orientation of the sample surface, is the angle between the normal of the surface and the incident and diffracted beam bisector, which is also the angle between the normal to the diffracting lattice planes and the sample surface [2].

Diffraction occurs at an angle $2 \theta$, which is defined by Bragg's Law: $n \lambda=2 d \sin \theta$, where $\mathrm{n}$ is a number denoting the order of diffraction, $\lambda$ is the X-ray wavelength, $\mathrm{d}$ is dimension of the lattice spacing of crystal planes, and $\theta$ is the diffraction angle. For the monochromatic $\mathrm{X}$-rays produced by the metallic target of an X-ray tube, the wavelength is known to 1 part in 105 . Any change in the lattice spacing $d$ results in a corresponding shift in the diffraction angle 2 $\theta$. Figure 1a shows the sample in the $\psi=0$ orientation. The presence of a tensile stress in the sample results in a Poisson's ratio contraction, reducing the lattice spacing and 
slightly increasing the diffraction angle, $2 \theta$. If the sample is then rotated through some known angle $\psi$ (Fig. 2b), the tensile stress present in the surface increases the lattice spacing over the stress-free state and decreases $2 \theta$. Measuring the change in the angular position of the diffraction peak for at least two orientations of the sample defined by the angle $\psi$ enables calculation of the stress present in the sample surface lying in the plane of diffraction, which contains the incident and diffracted X-ray beams. To measure the stress in different directions at the same point, the sample is rotated about its surface normal so that the direction of interest coincides with the diffraction plane. Because only the elastic strain changes the mean lattice spacing, only elastic strains are measured using X-ray diffraction for the determination of macroscopic stresses. When the elastic limit is exceeded, further strain results in dislocation motion, disruption of the crystal lattice, and the formation of microscopic stresses, but no additional increase in macroscopic stress. Although residual stresses result from non-uniform plastic deformation, all residual macrostresses remaining after deformation are necessarily elastic $[2,9]$.

\section{Experiment conditions}

Experiment was performed on constructional non-doped steel C56E2, which is used for production of bearing rings and other rolling parts of bearings. This steel is also suitable for production of shafts, gear wheels, pivots etc. It is characterized by worse weldability, and it is used mostly for production of parts with higher wear resistance.

Sample for the experiment was machined by turning technology on CNC turning centre. We monitored the residual stress with constant cutting speed $\left(\mathrm{v}_{\mathrm{c}}=50 \mathrm{~m} \cdot \mathrm{s}^{-1}\right.$ for roughing and $\mathrm{v}_{\mathrm{c}}=75 \mathrm{~m} \cdot \mathrm{s}^{-1}$ for finishing $)$ and depth $\left(\mathrm{a}_{\mathrm{p}}=2 \mathrm{~mm}\right.$ for roughing and $\mathrm{a}_{\mathrm{p}}=0.5 \mathrm{~mm}$ for finishing $)$ and increasing values of feed $(\mathrm{f}=0.17 \div 0.55 \mathrm{~mm}$ for roughing and $\mathrm{f}=0.05 \div 0.1 \mathrm{~mm}$ for finishing). The measuring of residual normal and shear stress was performed with Proto XRD diffractometer (Fig. 3) and electro-chemical polisher for removing of minimal layers of surface up to $200 \mu \mathrm{m}$.

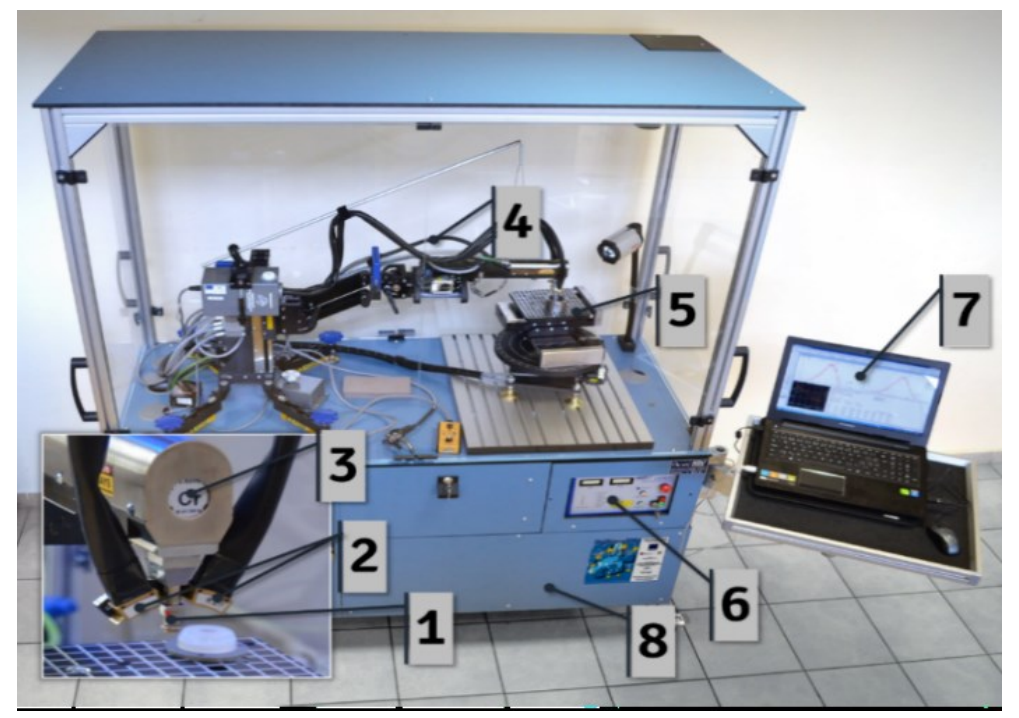

Fig. 3. X-ray diffraction residual stress measurement system (stationary: 1 - collimator; 2 - two detectors for diffraction cone; 3 - X-ray tube; 4 - Cobralink ${ }^{\circledR}$ flexible arm; 5 - positionable and rotary table; 6 - control unit; 7 - PC with software; 8 - laboratory stand 
From the theory of elasticity, the relationship between residual stress $(\sigma)$ and strain $(\varepsilon)$ on the sample surface under plane stress is given by the Bragg equation, $\lambda=2 \mathrm{~d} \sin \theta$, relating incident X-ray wavelength $(\lambda)$, lattice inter-planar spacing $(d)$ and diffraction angle $(\theta)$ (Fig. 4). The direction of maximum residual stress, that can be tensile or compressive, is assumed to occur in the cutting direction during most machining operations.

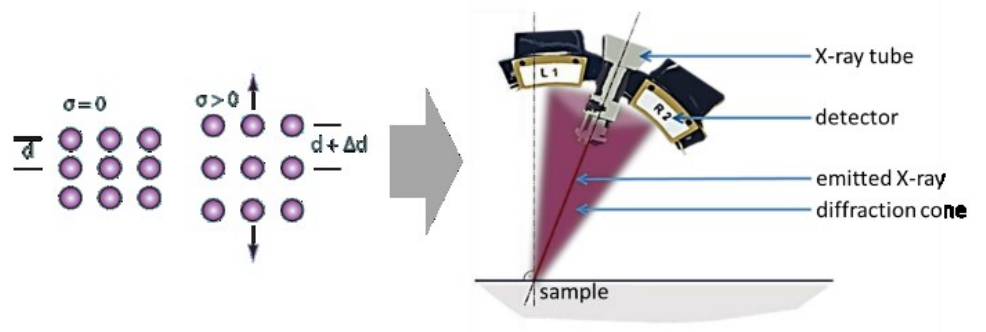

Fig. 4. Principle of measuring of residual stress by X-ray diffractometry based on Brag's Law

\section{Results of experiments}

Input data for simulation were measured as cloud of points or square map $(10 \times 10 \mathrm{~mm})$ consisting from point regularly disposed within its. Measurements were made in surface layer (depth of $0 \mathrm{~mm}$ ) and regular subsurface layers up to $200 \mu \mathrm{m}$. On the following figures, it can be seen the selected courses of normal residual stress through the measured depth in one place (at one point).

Selected figures (Fig. 5 and 6) present the courses of residual stress through the measured depth. Almost all cases, with the given cutting conditions, has similar course. In the surface layer and higher subsurface layers, the residual stress had compressive character. With the increasing depth, these residual stress decreased, or changed character to the tensile.

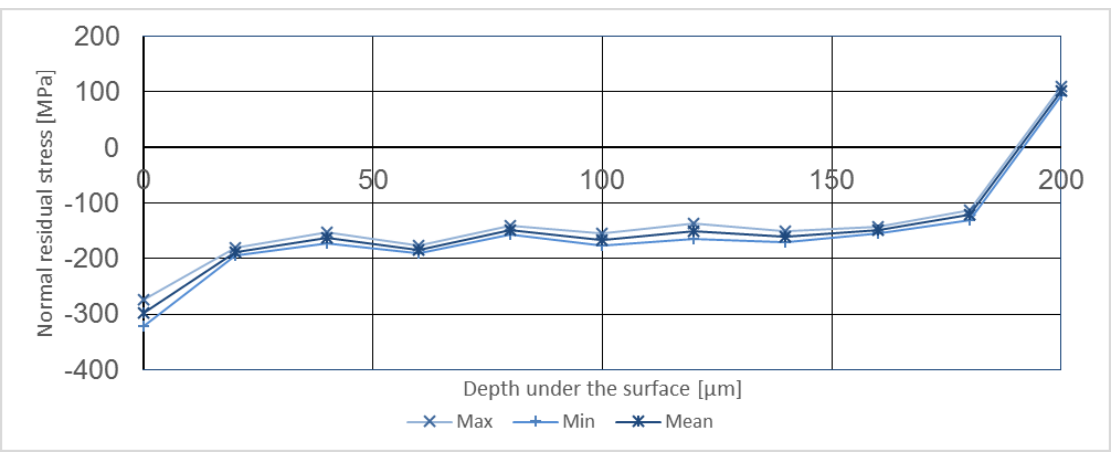

Fig. 5. Measured values of normal residual stress into the depth after roughing (cutting conditions: $\mathrm{v}_{\mathrm{c}}=50 \mathrm{~m} \cdot \mathrm{s}^{-1}, \mathrm{f}=0.17 \mathrm{~mm}, \mathrm{a}_{\mathrm{p}}=2 \mathrm{~mm}$ ) 


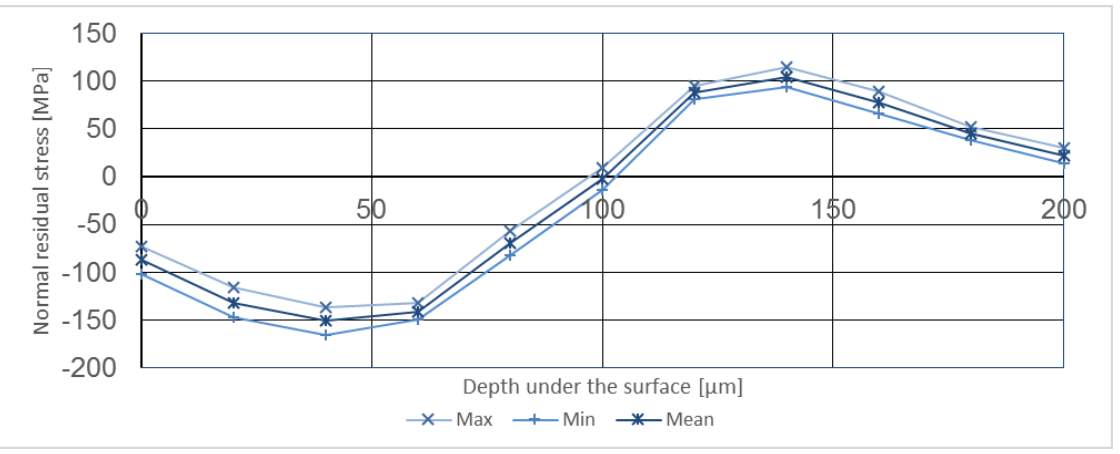

Fig. 6. Measured values of normal residual stress into the depth after finishing (cutting conditions: $\mathrm{v}_{\mathrm{c}}=75 \mathrm{~m} \cdot \mathrm{s}^{-1}, \mathrm{f}=0.05 \mathrm{~mm}, \mathrm{a}_{\mathrm{p}}=0.5 \mathrm{~mm}$ )

From measured data, there was computed via statistical software simulation of distribution of normal residual stress in three directions: direction of cutting speed, direction of cutting feed (or speed of cutting feed) and direction of depth. Subsequently, there were generated $3 \mathrm{D}$ graphs of these distributions.

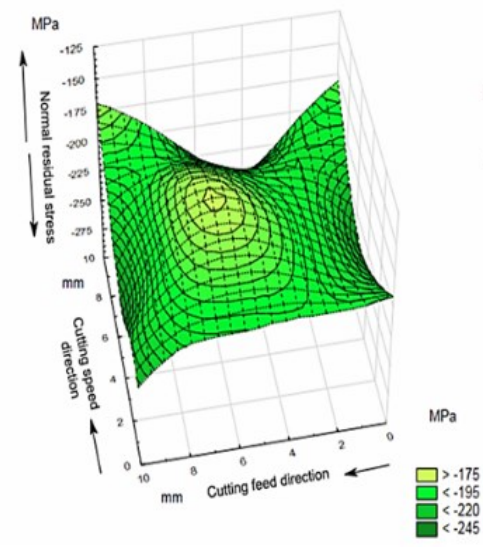

a)

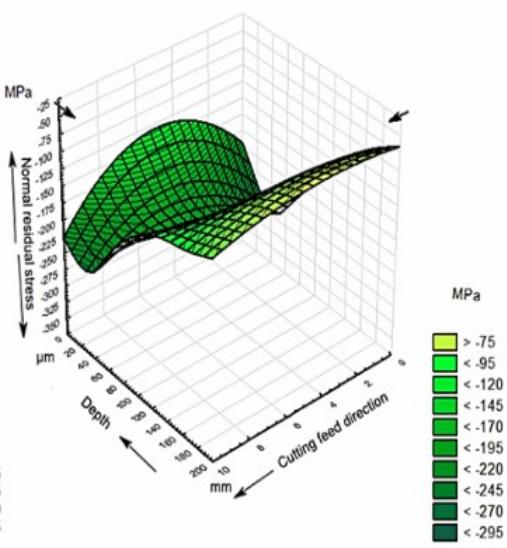

b)

Fig. 7. Simulation of distribution normal residual stress in various direction after roughing operations (cutting conditions: $\mathrm{v}_{\mathrm{c}}=50 \mathrm{~m} \cdot \mathrm{s}^{-1}, \mathrm{f}=0.37 \mathrm{~mm}, \mathrm{a}_{\mathrm{p}}=2 \mathrm{~mm}$ )

3D simulation of distribution of normal residual stress after roughing operations shows changes of normal residual stress in surface layer in direction of cutting speed and cutting feed (Fig. 7a). It can be seen no step changes: normal residual stress is in range between $175 \mathrm{MPa}$ and $245 \mathrm{MPa}$ with compressive character. Roughing operations with cutting depth $2 \mathrm{~mm}$ are relatively suitable for next finishing operations without inheritance of visible signs of possible rise of errors. Simulation into the depth (Fig. 7b) of part material shows in deeper layers, residual stress with tensile character and range of values of very large (from $292 \mathrm{MPa}$ of compressive residual stress up to $74 \mathrm{MPa}$ of tensile residual stress). The risk of rise of errors is increased, but in many causes it can be improved by finishing operations or other treatments of surface. 


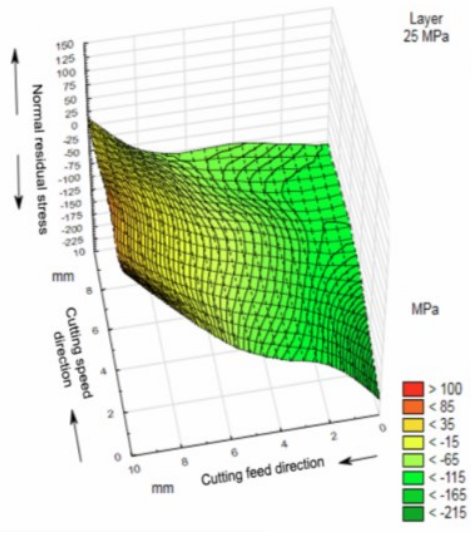

a)

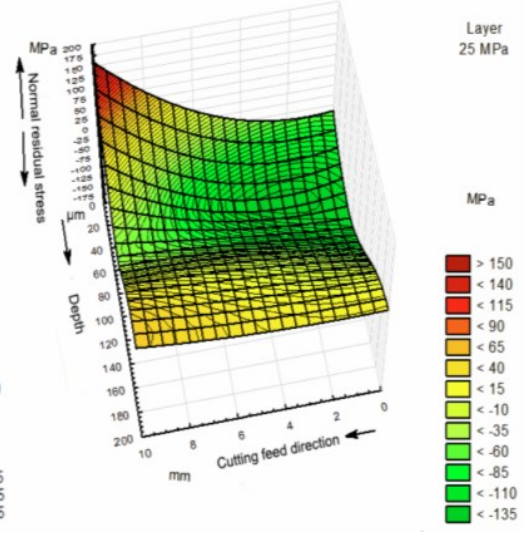

b)

Fig. 8. Simulation of distribution normal residual stress in various direction after finishing operations (cutting conditions: $\mathrm{v}_{\mathrm{c}}=75 \mathrm{~m} \cdot \mathrm{s}^{-1}, \mathrm{f}=0.05 \mathrm{~mm}, \mathrm{a}_{\mathrm{p}}=0.5 \mathrm{~mm}$ )

Simulation of distribution normal residual stress, for finishing operations, shows rise of tensile residual stress with direction of cutting feed (Fig. 8a). It can be caused by gradual increase in the volume of extruded material by the cutting tool due to relatively low cutting depth $\left(a_{p}=0.5 \mathrm{~mm}\right)$. Simulation into the depth (Fig. 8b) shows increased appearance of residual stress with tensile character. Range of normal residual stress on surface layer and deepest measured layer $(200 \mu \mathrm{m})$ is very large again. It is not suitable for final state of part. This problem can be solved via improvements of surface and subsurface layers by applying other finishing methods such as shot peening.

\section{Conclusions}

Measuring of residual stress is actual problem by which we can predict the functional properties of parts. Some destructive methods allow to measure residual stress in subsurface layers, but due to its principles, they are not so detailed and accurate. Principles of X-ray diffraction can measure the residual stress at microstructure levels and so push the boundaries of measuring in this area. Automation of this device allows to measure not only individual points or small lines, but we can obtain cloud of points or maps of residual stress distribution. Through the mathematical-statistical procedures, we can minimalize the number of required measured points and so create sufficiently precise simulations of residual stress distribution. And finally, from this data we can see detailed course of residual stress depending on cutting conditions into the depth of machined material. In showed experiments, we can see, that course of residual stress can be changed dramatically in range of several micrometres. Applying by this simulations, we can design suitable cutting conditions and so to minimalize rise of potential errors, which can cause formation of cracks and subsequent failures.

This article was funded by the University of Žilina project APVV 15-0405 - "Complex use of X-ray diffractometry for identification and quantification of functional properties of dynamically loaded structural elements from important technical materials" and project of University of Zilina: OPVav2009/2.2/04-SORO number (26220220101) - "Intelligent system for nondestructive technologies on evaluation for the functional properties of components of X-ray diffraction" and KEGA project 025ŽU-4/2017 Integration of innovative detectional-visaulization multi-disciplinary technologies as on-line tool for learning of progressive $\mathrm{CNC}$ technologies. 


\section{References}

1. C. A. Griffiths, Closing the Loop on Product Integrity on Bearings with Engineered Source Approval. (Split Ballbearing Features, Company Newsletter, 1989)

2. N. Ganev, I. Kraus, X-ray diffraction measurement of residual stresses. Material Structure 9 (2), (2002)

3. K. Tiitto, et al., Testing Shot Peening Stresses in the Field. The Shot Peener 4, ISSN 1069-2010 (1991)

4. R. Cep, J. Petru, T. Zlamal, J. Valicek, M. Harnicarova, A. Janasek, L. Cepova, Influence of feed speed on machined surface quality. $22^{\text {nd }}$ International Conference on Metallurgy and Materials, Conference proceedings, ISBN 978-808729441-3, 1033-1038 (2013)

5. Z. Pala, K. Kolarik, N. Ganev, J. Capek, Study of residual stress surface distribution on laser welded steel sheets. on 51st Annual of the International Scientific Conference on Experimental Stress Analysis, EAN (2013)

6. M. Handrik, P. Kopas, V. Baniari, M. Vaško, M. Sága, Analysis of stress and strain of fatigue specimens localised in the cross-sectional area of the gauge section testing on bi-axial fatigue machine loaded in the high-cycle fatigue region. Procedia Engineering 177, 516-519 (2017)

7. P. S. Prevéy, X-ray Diffraction Residual Stress Techniques. Metals Handbook 10, Metals Park: American Society for Metals, p. 380-392 (1986)

8. M. E. Fitzpatrick, et.al., Determination of Residual Stresses by X-ray Diffraction. Measurement Good Practice 52, National Physical Laboratory, Teddlingtoon

9. A. Czan, M. Sajgalik, A. Martikan, V. Kuzdak, Identification of residual stress and structure properties in surface and subsurface layers of austenitic steel designed for nuclear energetics. EAN $2015-53^{\text {rd }}$ Conference on Experimental Stress Analysis, 36-40, ISBN 978-800105734-6 (2015)

10. M. Brezina, L. Kupca, Stress corrosion cracking of austenitic stainless steel in a nuclear power plant enviroment. Enviroment inducted cracking of materials. Department of Structural Analysis, VUJE Inc, Trnava, 431-436 (2008)

11. A. Gorog, D. Stancekova, M. Kapustova, I. Gorogova, I. Miturska, Influence of Selected Cutting Conditions on Cutting Forces. Advances In Science And TechnologyResearch Journal 11 (1), 179-185, ISSN 2299-8624

12. A. Czan, E. Tillova, J. Semcer, J. Pilc, Surface and subsurface residual stresses after machining and their analysis by X-ray diffraction. Comunications 15 (2), 69-76 (2013)

13. D. Mital, J. Zajac, Z. Mitalova, Monitoring influence of selected parameters on surface quality after polymer powder coating. MM Science Journal 2016 (October), 1077-1081 (2016)

14. N. Náprstková, F. Holešovský, Admeasurement of Grinding Wheel Loss at FPTM. $24^{\text {th }}$ International Colloquium (Advanced manufacturing and repair technologies), 159-164, ISBN 978-80-7194-962-6 (2007)

15. P. Martikan, M. Drbul, J. Holubjak, J. Mrazik, R. Joch, The Issue of Determining the Geometric Position Deviation of the Threaded Holes. Advances in Science and Technology-Research J. 10 (32), 47-52 (2016)

16. R. Cep, A. Janasek, J. Petru, L. Cepova, A. Czan, J. Valicek, Hard Machinable Machining of Cobalt-based Superalloy. Manufacturing Technology XIII (13), UJEP: Ústi n. Labem, 226-231, ISSN 1213-2489 